Prepared for the U.S. Department of Energy

under Contract DE-AC05-76RL01830

\title{
Second Line of Defense Megaports Initiative Operational Testing and Evaluation Plan Colón Container Terminal (CCT) Panama
}

RN Newhouse

January 2010

Pacific Northwest

NATIONAL LABORATORY

Proudly Operated by Battelle Since 1965 


\title{
DISCLAIMER
}

This report was prepared as an account of work sponsored by an agency of the United States Government. Neither the United States Government nor any agency thereof, nor Battelle Memorial Institute, nor any of their employees, makes any warranty, express or implied, or assumes any legal liability or responsibility for the accuracy, completeness, or usefulness of any information, apparatus, product, or process disclosed, or represents that its use would not infringe privately owned rights. Reference herein to any specific commercial product, process, or service by trade name, trademark, manufacturer, or otherwise does not necessarily constitute or imply its endorsement, recommendation, or favoring by the United States Government or any agency thereof, or Battelle Memorial Institute. The views and opinions of authors expressed herein do not necessarily state or reflect those of the United States Government or any agency thereof.

\author{
PACIFIC NORTHWEST NATIONAL LABORATORY \\ operated by \\ BATTELLE \\ for the \\ UNITED STATES DEPARTMENT OF ENERGY \\ under Contract DE-AC05-76RL01830
}

Printed in the United States of America
Available to DOE and DOE contractors from the Office of Scientific and Technical Information,
P.O. Box 62, Oak Ridge, TN 37831-0062;
ph: (865) 576-8401
fax: $(865) 576-5728$
email: reports@adonis.osti.gov

\footnotetext{
Available to the public from the National Technical Information Service, U.S. Department of Commerce, 5285 Port Royal Rd., Springfield, VA 22161 ph: (800) 553-6847 fax: $(703) 605-6900$ email: orders@ntis.fedworld.gov online ordering: http://www.ntis.gov/ordering.htm
}

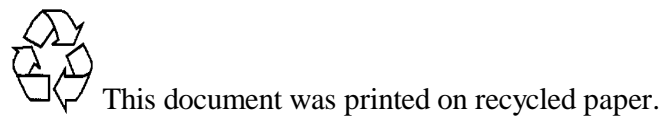




\section{Second Line of Defense Megaports Initiative Operational Testing and Evaluation Plan}

\section{Colón Container Terminal Panama}

RN Newhouse

January 2010

Prepared for

the U.S. Department of Energy

under Contract DE-AC05-76RL01830

Pacific Northwest National Laboratory

Richland, Washington 99352 


\section{Acronyms and Abbreviations}

CAS

CCT

ConOps

CSI

DGA

DOE

ISO

LANL

LAS

LMP

MDQ

MIT

NII

NNSA

NORM

OCR

OJT

OT\&E

PNNL

RIID

RPM

SIS

SLAT

SLD

SNL

SOP

SWS

TMP

TOS

TSA

central alarm station

Colón Container Terminal

Concept of Operations

Container Security Initiative

Panama Direccion General de Aduanas (Panama Customs)

U.S. Department of Energy

International Standards Organization

Los Alamos National Laboratory

local alarm station

local maintenance provider

minimum detectable quantity

Manzanillo International Terminal

non-intrusive inspection

National Nuclear Security Administration

naturally occurring radioactive material

optical character recognition

on-the-job training

Operational Testing and Evaluation

Pacific Northwest National Laboratory

radioisotopic identification device

radiation portal monitor

secondary inspection site

System Level Acceptance Testing

Second Line of Defense

Sandia National Laboratories

Standard Operating Procedure

secondary workstation

Training Management Plan

terminal operating system

TSA Systems, Ltd. 



\section{Glossary}

Alarm: An alarm is a particular type of event raised in the Megaports central alarm system (CAS) system that requires immediate action/attention by the system operators [i.e., CAS, local alarm station (LAS), and secondary workstation (SWS)] in accordance with the workflow defined for the system.

Alert: An alert is a visual notification issued by the Megaports CAS System to the operators (i.e., CAS, LAS, and SWS) intended to bring their attention to a particular event. Alerts can come in the form of pop-up windows, audible tones, and/or visual cues, such as flashing, colored entries in the event queues. Which forms are displayed depends on how the system is configured.

CAS: A CAS is a central control location where the alarm and event evaluation for a given collection of terminals (with associated Control Points and Inspection Sites) is undertaken by designated host country staff.

CAS System: The CAS system (also referred to as the "Communications System") provides those capabilities required to accept, process, display and store data from RPMs; provide images to support alarm and fault event resolution; and to provide interfaces allowing the CAS system users to effectively manage the alarm/event processing (i.e., respond to alarm and fault events) and to assess the status of the sites supported by the system.

CAS Workstation: A CAS workstation is a computer workstation located at a CAS location that is used by the host country staff members to access the CAS system.

Container Security Initiative (CSI) Workstation: A CSI workstation is a computer workstation located at the CSI location used by CSI personnel to access the CAS system.

EDIFacts: An International Standards Organization (ISO) messaging protocol supporting exchange of messages between businesses. The standard defines the content and format of many different types of messages. Message support for the exchange of information between shippers, shipping agents, terminal operators, and Customs agencies is included as part of this standard.

Event: An event in the CAS system occurs when one of the monitoring devices (i.e., radiation portal monitors [RPMs], cameras) sends a message associated with a particular event as its trigger. In addition, CAS system events can be triggered by system objects, such as the status of health ( $\mathrm{SOH}$ ) monitoring components. Events can include radiation alarms, radiation faults and tamper faults generated by the RPMs, and SOH faults (e.g., camera faults or portal faults) generated by the CAS SOH component.

Fault Alarm: A fault alarm is a type of event generated when an unusual equipment condition is detected.

Gate: An access point (entry and/or exit) to a particular site. This term is commonly used to describe an access point to a shipping terminal. Typically, a gate will have one or more lanes with traffic passing through. 
Local Alarm Station: A LAS is the location at a terminal gate where the terminal alarm and eventprocessing activity assigned to the staff at these gates is undertaken. Typically, LASs are located at terminal exit gates primarily to ensure that container traffic that causes an alarm is halted prior to departure from the terminal area. The LAS staff will then follow directions provided by the CAS operators regarding further processing, such as sending the traffic to secondary inspection or releasing the traffic.

LAS Workstation: A LAS workstation is a computer workstation located at each LAS location and is used by staff members who are assigned LAS roles to access the CAS system.

Multiple Alarms: The term "multiple alarms" (or "multiple events per occupancy/inspection") is used to describe the scenario where the CAS system control point (i.e., a particular RPM) is configured to permit multiple alarms to be associated with a single event (or occupancy). Typically, only a single alarm is associated with an event or occupancy.

Occupancy: Also known as a primary inspection, occupancy occurs when a vehicle passes through a system sensing device, typically an RPM, triggering it to record data that pertain to the occupant.

Pillar: A pillar, master and/or slave, is the major sub-unit of an RPM that contains the actual radiation sensors, occupancy sensor, and speed sensor.

Radiation Portal Monitor: The term RPM is used to refer to the sensor device installed at a control point through which traffic passes. Typically, these devices are fixed radiation monitors with one or more pillars, usually a master pillar and a slave pillar. There are pedestrian, vehicle, and rail-fixed RPMs as well as mobile RPMs that can be used for pedestrians or vehicular traffic.

Primary Inspection Site: A primary inspection site is the location where people, vehicles, or railcars pass through sensor devices, such as RPMs, that detect any nuclear-related materials.

Radiation Alarm: A radiation alarm is an event generated by an RPM when the level of gamma or neutron radiation exceeds the configured threshold level during occupancy.

Radiation Fault: A radiation fault is an event generated by an RPM when the level of gamma or neutron radiation exceeds the configured threshold level when the RPM is unoccupied.

Secondary Inspection: A secondary inspection is the examination of traffic of interest with the purpose of identifying the location and type of radiation already detected by an RPM. It is an in-depth process performed using a handheld radiation detector or radioisotopic identification device (RIID).

Secondary Inspection Site (SIS): An SIS is the site where people, vehicles, or cargo that generated an alarm event have a secondary inspection conducted by staff assigned to this role.

Secondary Workstation (SWS): An SWS is the computer workstation used by staff conducting the secondary inspection to update the Megaports system with the secondary inspection assessments and results. 
Simultaneous Alarms: The term "simultaneous alarms" is used to describe the scenario where more than one alarm is raised (from multiple RPMs) at the same time in the CAS system. The CAS system must be able to properly prioritize, queue, and track all alarms.

Tamper Alarm: A tamper alarm is raised when the access doors to an RPM are opened, power is lost at the RPM (requiring conversion to backup power), or the RPM backup power charger output is below minimum required levels. If the CAS system includes limit switches (i.e., sensors detecting open/closed conditions) on doors, gates, etc., then an "open" condition in the limit switch also generates a tamper alarm.

Terminal Operating System (TOS): The TOS is the software system utilized by terminal operators to support their operations. This includes tracking containers, developing loading plans for ships, etc. The EDIFacts messages generated by the Megaports system will be sent to the terminal operators' TOS systems.

Timer: A timer is a property that can be associated with a particular workflow step in an event to track the elapsed time between the end of that workflow step and the beginning of the next workflow step. When the timer expires, the system automatically issues an alert to the operators. A typical example of a timer would be between the end of the workflow step where a vehicle at a gate is sent by the LAS operator to an SIS and the next workflow step where the SWS operator acknowledges the arrival of the vehicle at secondary inspection. If the vehicle had not arrived and been acknowledged by the SWS operator by the time configured for the timer, the system would generate a timer alert to bring the situation to the attention of the system operators. 



\section{Contents}

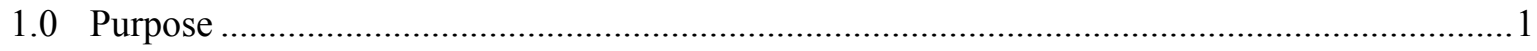

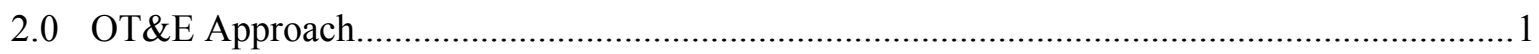

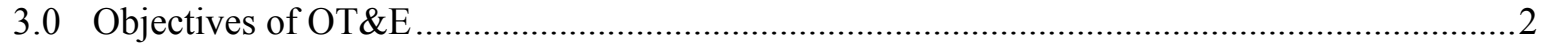

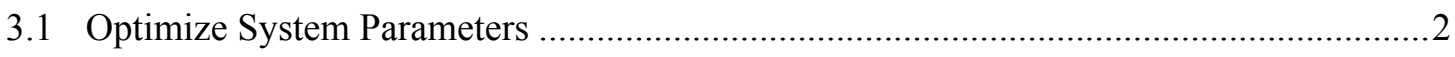

3.2 Assess Operator Performance and Finalize Training .................................................

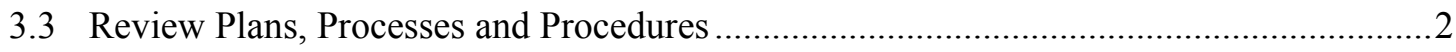

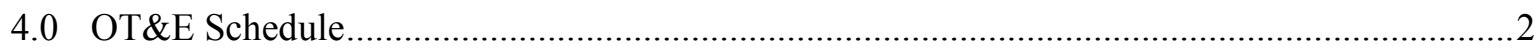

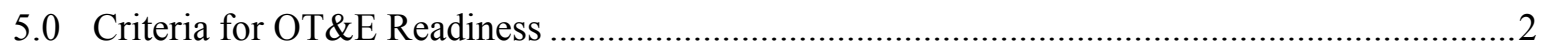

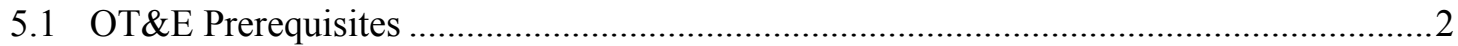

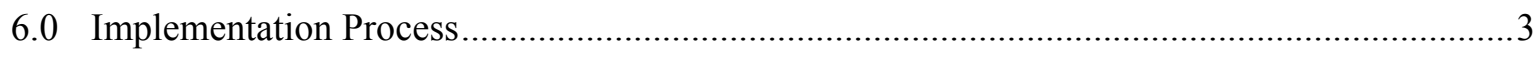

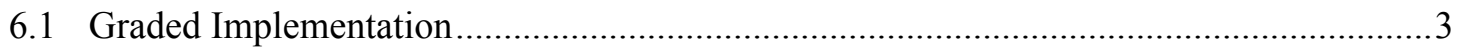

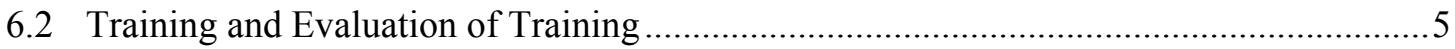

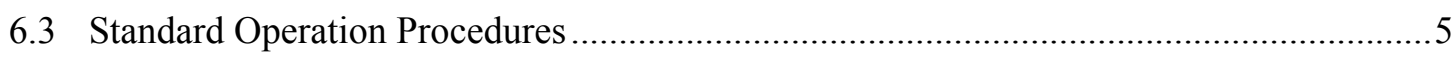

6.4 Determination and Setting of RPM Alarm Threshold.......................................................5

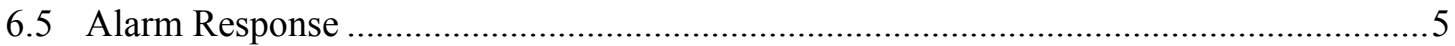

7.0 Organizational Responsibilities and Deliverables ......................................................... 6

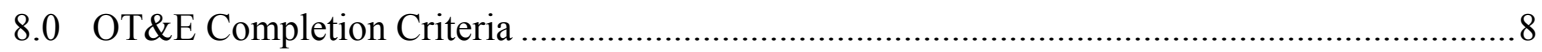

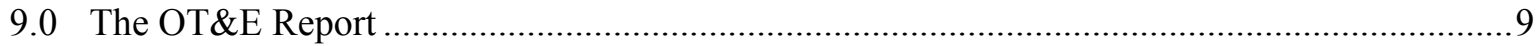

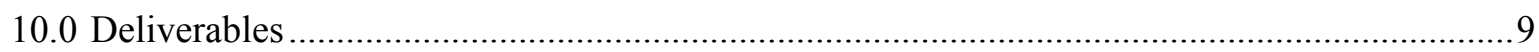

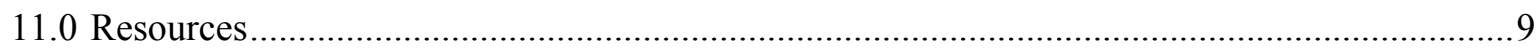

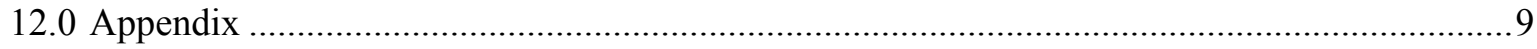




\subsection{Purpose}

The purpose of Operational Testing and Evaluation (OT\&E) is to validate and baseline an operable system that meets the Second Line of Defense (SLD) mission requirements. An SLD system is defined as the detection technology and associated equipment, the system operators from the host country, the standard operating procedures (SOPs), and other elements such as training and maintenance which support long-term system sustainment.

To this end, the activities conducted during the OT\&E phase must demonstrate that the Megaports System can be operated effectively in real-time by Panama Direccion General de Aduanas (DGA-Panama Customs) personnel to the standards of the U.S. Department of Energy/National Nuclear Security Administration (DOE/NNSA). The activities conducted during the OT\&E phase will also determine if the Megaports System, as installed and accepted, is performing according to the Megaports Program objectives such that the optimal balance is achieved where target materials are reliably detected and innocent alarms are minimized to the greatest extent possible.

The OT\&E phase of the project also provides an opportunity to consider potential improvements to the system and to take remedial actions if performance deficiencies are identified during the course of evaluation. The OT\&E Report serves as a tool that summarizes the status of the entire system at the end of project implementation and is utilized by a sustainment team or other program stakeholders to modify or revise the sustainment strategy.

DOE/NNSA will determine that OT\&E is complete by examining whether the Megaports System is performing as intended and that DGA is fully capable of operating the system independently from continuing onsite support from the U.S. team.

\subsection{OT\&E Approach}

The project team, in close cooperation with system operators, reviews procedural compliance and evaluates operator response to events and alarms as the system operates in a production mode. Recommendations for improvements are made when appropriate. CCT is the third port in Panama to participate in the Megaports Initiative. DGA has been operating Megaports installations at two other two ports--Balboa, in Panama City, and Manzanillo International Terminal (MIT) in Colón--since fall 2008. Furthermore, the local maintenance provider, Inmaquip Panama S.A. (INMAQUIP), has been providing all routine and non-routine maintenance at Balboa and MIT and is under contract to perform the maintenance at CCT.

Initially, the DGA plans to use the radiation portal monitors (RPMs) when a container is targeted for the Container Security Initiative's (CSI) imaging equipment. The installation at CCT consists of one vehicle RPM and one CAS workstation.

The OT\&E approach at CCT will be tailored to consider the experience and training of the operators, the complexity of the installation, the experience of the local maintenance provider and the maturity of the Panamanian support of the Megaports program. 


\subsection{Objectives of OT\&E}

The objective of this OT\&E Plan is to turn over the DOE/NNSA-provided Megaports System to DGA at the conclusion of the OT\&E phase of the project, thereby formally starting the sustainable operation phase of the project. This turnover will be achieved through the courses of action outlined below.

\subsection{Optimize System Parameters}

Radiation portal monitor (RPM) alarm thresholds are adjusted during OT\&E in order to achieve maximum detection of special nuclear materials and other radioactive materials while generating the minimum number of innocent alarms. Other system components such as optical character recognition (OCR) and associated components are evaluated for accuracy and reliability and adjustments are recommended if necessary.

\subsection{Assess Operator Performance and Finalize Training}

System operators are observed during real-time operations. They are evaluated on procedural compliance, accuracy, and ability to respond to different operational situations. Additional training is provided as necessary to ensure operators demonstrate adequate knowledge and operational skills.

\subsection{Review Plans, Processes and Procedures}

Plans, processes and standard operating procedures are reviewed to ensure appropriate mechanisms are in place for sustained operation of the detection system and continuing operator training and assessment. These should include procedures for system maintenance; provisions for appropriate power and communications services to run the system; agreed-upon data sharing and analyses activities; procedures for response to alarms that require in-country technical support or source recovery; and planning for continuing cooperation between the partner country and the SLD program.

\subsection{OT\&E Schedule}

The system at Colón Container Terminal (CCT) passed the Systems Level Acceptance Testing (SLAT) on December 18, 2009 and was deemed operational. The OT\&E activities for the Colón Container Terminal (CCT) will commence on January 19, 2010. The duration of OT\&E activities should not exceed two days.

\subsection{Criteria for OT\&E Readiness}

\subsection{OT\&E Prerequisites}

The following activities should be completed and all associated completion criteria met prior to conducting OT\&E. Any activity not completed or criteria not met should be managed as high risk as it will have a high potential to impact schedule, cost, and quality.

Readiness Review - An OT\&E readin ess review was conducted prior $t$ o commencement of OT\&E, and the following items completed: 
- System operators have received classroom training

- Maintenance providers have received required training

- Site procedures or SOPs have been drafted and reviewed

- U.S. project team and host countr y team staffing plans ha ve been prepared and are coordinated with the OT\&E Plan

- Coordination with the $\mathrm{h}$ ost country site authority and other host country stakeholders has occurred

- The OT\&E Plan has been approved by the DOE/NNSA

Completion of SLAT and Acceptance Testing - SLAT activities were completed on December 18, 2009. DOE/HQ's issued the SLAT Report to the prime contractor, SES-TECH, on January 11, 2010. There were one CAS System failure six Test Plan failures. The CAS System failure is that the message board does not display the "proceed to secondary inspection" message in time for the driver to see the message before he passes the sign. Until this failure is resolved, the CAS operators will have to develop an operational solution in order to notify the drivers to proceed to secondary inspection. This operational solution will be discussed and reviewed during OT\&E. The other six failures are construction punch list items that will not affect the operation of the installation. SESTECH's corrective action plan addressing the failures will be completed prior to the start of OT\&E.

Operator Training - All in-country operator training has been conducted as planned. Operator training, train-the-trainer, and source recovery training (for a smaller Customs team) has been conducted in accordance with the Training Management Plan (TMP). Refresher training will be conducted for the operation of source recovery equipment.

Maintenance Training - The local maintenance provider, INMAQUIP, has extensive experience on all parts of the system and has received communications systems training from the software provider, Schneider Electric, and the optical character recognition (OCR) provider, APS Systems. INMAQUIP has been acting as the de-facto system administrator at Balboa and will be taking that responsibility at CCT as well.

Site Procedures / SOPs - Site procedures are in use at Balboa and MIT and will be reviewed for CCT during OT\&E, ensuring refinements are discussed and incorporated.

Data Sharing Arrangement - The current data sharing arrangement for Balboa and MIT extends to CCT.

U.S. Team Member Briefing - Due to the maturity of the Megaports Initiative in Panama, the OT\&E team consists of only two team members. Loren Byers from Los Alamos National Laboratory and Roy van Wormer from Pacific Northwest National Laboratory will be conducting the OT\&E. The team has reviewed project team safety measures, team and stakeholder contact information, country specific Concept of Operations (CONOPS), operation of the communication system, system configuration, and the OT\&E Plan.

\subsection{Implementation Process}

\subsection{Graded Implementation}

A graded approach has been utilized in developm ent of the OT\&E plan for CCT. Several variables are considered when determining the specific re sources required and the content and the duration of OT\&E and these variables are listed below. 
- Number of operators - Each operator needs a sufficient amount of expo sure to real-time operation of the system and OJT opportunities. The number of operators contributes to the U.S. project team resource requirements and time required on site. The re are five operators currently assigned to CCT. Preliminary staffing level is two at any one time.

- Operator skills - When deter mining the content a nd level of support necessary to conduct OT\&E, the skill of system operators should be considered. Initially, operators in some countries may not even have had the basic computer skills required to operate the system. It is essential that operators and their abilities are evaluated to en sure they can demonstrate sufficient knowledge and skill to operate the system in a safe and eff ective manner. All five oper ators at CCT have experience working with computers. The supervisor of the CAS at CCT, Ms. Evestania Escobar, was previously the superv isor at MIT and has significant operational experience. Three of the remaining four staff me mbers have received operator training and two on the staff have recei ved train-the-trainer.

- Operational shifts - Systems that o perate on multiple shifts each day may require a larger training effort. The deplo yment of U.S. project team resources in support of evening or night shifts is not ideal and may introduce unnecessary security risks. The most appropriate method may include temporary transfer of resources to a single day shift. In addition, site logistics such as training rooms, transportation, interpreter availability, and security must be considered. The CAS at CCT is operated Monday through Saturday from 8-4 pm.

- Indigenous trainers -Availability and use of indigenous, capable trainers. As noted previously, Panama has 14 months of experience with the Megaports system at MIT and Balboa and as a result has received $\mathrm{m}$ ultiple training classes. There have been two train-the-trainer courses conducted, with the $\mathrm{m}$ ost recent being in $\mathrm{N}$ ovember 2009. The attendees of that course conducted operator training at CCT during the we ek of Decemb er 14-18, 2009, and this was observed by a PNNL trainer. All planned opera tor training has been conducted. An additional source recovery exercise with supplemental refr esher training is currently planned for late February 2010.

- Volume and type of system traffic - A high volume of traffic allows for more interactions with transits by the operators. Volume also impacts the length of time needed to meet the minimum number of occupancies required to perform final threshold setting calculations. Additionally, the type of cargo transiting $t$ he system will affect the num ber of opportunities operators have to respond to alarms. Both volume and cargo type impact U.S. project team resource requirements and the duration of OT\&E. Currently, the only traffic going through the monitor is targ eted containers from the Container Securit y Initiative (CSI). This v olume is currently less than ten containers per day. Fortunately, the CCT CAS supervisor has had operational experience at MIT and will be present during $\mathrm{m}$ ost hours of operation. Threshold settings were adjusted based on background data obtained after the RP Ms were a ligned and before SLAT. Daily files will be analyzed prior to OT\&E, but it is not anticipat ed that there will be enough data to warrant changes to the settings.

- Site location - Some sites may be very remote presenting logistical challenges to the U.S. project team. A graded implementation of OT\&E may be required at these loc ations. CCT is loc ated approximately 3 kilometers from the operational Megaports installation at MIT. The CAS staffs at CCT and MIT know each other well and $\mathrm{m}$ aintain a close working relationship. Resources have been borrowed from MIT when needed for training, and the operato rs provide technical advice when needed. 


\subsection{Training and Evaluation of Training}

Training and evaluation of training was conducted the week of December 14-18, 2009. Staff members from the Ports at Cristobal and CCT were given operator training and training on use of the handhelds and conducted field exercises. The staff for the CCT site are: Evestania Escobar, Yasira Johnson, Katherine Franco, Nedelka Shoogreen (not trained), and Juan Alveo. With the exception of Nedelka Shoogren, all have received training. Evestania Esocobar is the supervisor at CCT and was previously supervisor at Manzanillo International Terminal. If training deficiencies are uncovered during the OT\&E phase of the project, remedial training will be provided or recommended as needed. Indigenous operator training capability exists in Panama and can be utilized if needed.

\subsection{Standard Operation Procedures}

An SOP will be made available to system operators to improve knowledge of operations, alarm response, and troubleshooting. The SOPs have been in use at Balboa and MIT and will be reviewed for adequacy at CCT. They will also be evaluated against any specific port rules or operational requirements implemented by the port operator, Colón Container Terminal, S.A. Concept of Operations will also be evaluated during OT\&E.

\subsection{Determination and Setting of RPM Alarm Threshold}

Using data gathered during the background radiation survey, RPMs are initially set up to minimize innocent alarms to the extent possible without affecting the ability to detect materials of interest. During the OT\&E phase of the project, additional data on the radiation characteristics of cargo containers handled at CCT will be accumulated, evaluated, and archived by LANL. However, CCT does not experience a high volume of traffic through the monitor. This may not provide enough data to conclude that adjustments are necessary. However, daily files will be analyzed prior to OT\&E and if possible, this data will either provide confirmation that the settings are optimal or provide the basis for adjustments to the RPM settings. This information will better balance the objectives of maintaining sensitivity for the detection of target materials while minimizing the impact on Port operations.

LANL will submit a one-page summary with recommended alarm threshold values and associated minimum detectable quantity (MDQ) values for each monitor prior to completion of OT\&E. The final settings will be documented in the OT\&E Report.

The optimization of other system parameters such as OCR or camera settings, traffic control equipment, frequency of preventative maintenance activities (e.g., camera lens cleaning, desiccant replacement), etc. will be evaluated and recommendations for adjustments will be made if necessary.

\subsection{Alarm Response}

The alarm response will be in accordance with CCT ConOps and SOP. If assistance is needed from the United States in resolving a neutron alarm, Appendix A (Appendix A - Neutron Incident Report Form) will be used to document the event. 


\subsection{Organizational Responsibilities and Deliverables}

The following are the organizational responsibilities and deliverables of the OT\&E phase of the project.

\section{DOE/NNSA}

The responsibilities of DOE/NNSA include the following:

- review and approve the OT\&E plan

- review and approve results of the OT\&E phase of the project

- turn system over to host country at conclusion of the OT\&E phase of the project

- identify and finalize the mechanism for maintenance of the Megaports System for a negotiated period of time.

Deliverables:

- System commissioned to the Government of Panama

\section{$\underline{\text { DGA (Panama Customs) }}$}

The responsibilities of DGA include the following:

- provide personnel to operate the DOE/NNSA-provided Megaports System in a simulated and fully operational environment

- provide DOE/NNSA OT\&E team with access to Port facilities and Port personnel to work in partnership to implement and complete the OT\&E plan

- provide oversight of radiation sources as necessary for OT\&E activities

- provide training support and services as identified in the TMP

- refine the SOP

- upon successful completion of the OT\&E phase of the project, accept and operate the system.

Deliverables:

- System accepted for operation

\section{$\underline{\text { Pacific Northwest National Laboratory (PNNL) }}$}

The responsibilities of PNNL include the following:

- provide project management for the OT\&E phase of the project in coordination with in-country logistical resources established during the construction phase

- continued implementation and evaluation of training plan

- prepare overall completion report for the OT\&E phase of the project 
- commissioning document review/acceptance.

\section{Deliverables:}

- OT\&E Plan

- OT\&E Report

- Completion documentation

\section{Los Alamos National Laboratory (LANL)}

The responsibilities of LANL include the following:

- in partnership with the host country, acquire and evaluate occupancy data, load data, and RIID inspection results to understand cargo types and associated NORM for imported, exported, and transshipped cargo

- document analysis of NORM and occupancy data to characterize terminal and portal dependence of innocent alarm rate versus alarm threshold and provide to PNNL for inclusion in the final OT\&E report to DOE/NNSA

- based upon occupancy data, determine parameters for RPM electronic alignment to ensure optimal screening of target special nuclear materials and minimization of innocent alarms with the objective of minimizing impact on Port operations

- implement recommended RPM electronic alignment

- support PNNL when training of Port personnel on critical operational capability; in particular, provide CAS operation expertise as needed

- download raw occupancy data for evaluation on a periodic basis to determine continued proper operation of the RPMs and to determine whether significant changes in NORM characteristics have occurred either due to seasonal variations or changes in shippers utilizing the Port

- support development and performance of exercises and scenarios.

- assess host-country capability to operate the communications system

\section{Deliverables:}

- Documented analysis of NORM and occupancy data

- Determine final threshold set points

- Country/Site Profile

\section{SES-TECH}

The responsibilities of SES-TECH include the following:

- provide continuing logistical support

- presence on-site only when requested for CCT OT\&E 


\section{TSA Systems, Ltd (TSA)}

The responsibilities of TSA include the following:

- provide consulting support as needed

- presence not required during OT\&E

Deliverables:

- Maintenance material/documents needed for monitors

\section{$\underline{\text { Schneider Electric }}$}

The responsibilities of Schneider Electric include the following:

- develop and deliver training materials for communications system operations (including the optical character recognition system) and system administrator

- provide consulting support as needed

- presence not required during OT\&E

\section{Deliverables:}

- Training materials for operators and system administrator

\subsection{OT\&E Completion Criteria}

This section discusses the activities that should be completed, at a minimum, and the criteria that should be met prior to exiting OT\&E.

Objectives - Meet the objectives of the OT\&E as described in section 3.0 of this plan.

Operator and Maintenance Manual - Operator and maintenance manuals, including parts list and as-built drawings are available for the LMP and CAS operators.

Maintenance Contract - Maintenance contracts are in place with in-country organizations.

The OT\&E assessment should not be considered complete until the follow ing items have been successfully completed:

- System parameters have been assess ed and dete rmined to be optimally balanced betw een detection capability and innocent alarm rate. Key parameters are documented and included in the final report.

- Operators have dem onstrated a satisfactor y level of knowledge and experience to operate the system in a ccordance with procedures and b est practices. A su mmary of the operator performance assessment is also documented in the final report.

- Processes and procedures are in place and fully implemented such that the system can be operated in a consistent and sustained manner. This includes but is not lim ited to: SOPs, local maintenance provider contracts, local training management plan, communication plan for data 
and seizure reporting, and agreements for system operating infr astructure, such as utility and communications services. A summary table of these items is included in the final report.

- A contact information list has been prepared a nd distributed that includes the designated lead system operator, local maintenance provider, system administrator, DOE/NNSA designated points of contact, SLD Help Desk, and U.S. and/or partner country reach-back contacts for alar m assessment assistance.

\subsection{The OT\&E Report}

The purpose of the report is to document the results of the OT\&E phase of the project, to evaluate the performance of the system and the host country operators, and to recommend any needed corrective action. The OT\&E final report will be submitted within three weeks after completion of OT\&E.

\subsection{Deliverables}

- OT\&E Report - The OT \&E final report $m$ ust be prepared and subm itted to the SLD countr y manager no later than 3 weeks after OT\&E.

- Country Profile - A country profile will be co mpleted for CCT, documenting all contact information, all deployed equipment, including handhelds, spare parts, RPM settings and the items from the Final Installation Report (i.e. as-bu ilt drawings, operator manuals). The country profile will be forwarded to the SLD H elp Desk and the LMP f or use during the sustainability phase.

\subsection{Resources}

PNNL is responsible for ensuring adequate staffing of the OT\&E.

LANL is responsible for assisting the OT\&E phase until it is determined that Panama Customs can operate the CAS without direct supervision.

\subsection{Appendix}




\section{Appendix A}

\section{Neutron Incident Report Form}

Incident Tracking Number:

Incident Location:

Date:

Time:

Reporting Technical Support Official:

Phone:

\section{Conveyance Information:}

Vehicle Type:

Make/Model:

License:

Country:

Number of Passengers:

Manifested Commodity:

Manifest or Placarding Information:

Any labels or placarding indicating radioactive or hazardous materials? YES NO

Shipment documents indicate industrial neutron source? YES NO

Shipper Name and Address:

Consignee Name and Address:

\section{Alarm Information:}

Radiation Alarm: Neutron ONLY or Neutron and Gamma

Peak Neutron Alarm Level displayed on CAS/LAS: _ _ _ _ cnts/sec

If present, Peak Gamma Alarm Level displayed on CAS/LAS ___ sigma 


$\begin{array}{lcr}\text { Has the vehicle been isolated? } & \text { YES } & \text { NO } \\ \text { Has a perimeter been established? } & \text { YES } & \text { NO } \\ \text { Has the source been located? } & \text { YES } & \text { NO } \\ \text { Has the source been isolated? } & \text { YES } & \text { NO }\end{array}$

Using the figure below,

1. Mark the location of neutron source based on CAS/LAS display,

2. Mark the location of the maximum response from hand-held detector and

3. Fill the oval shapes with measurements of hand-held neutron-responsive detector.
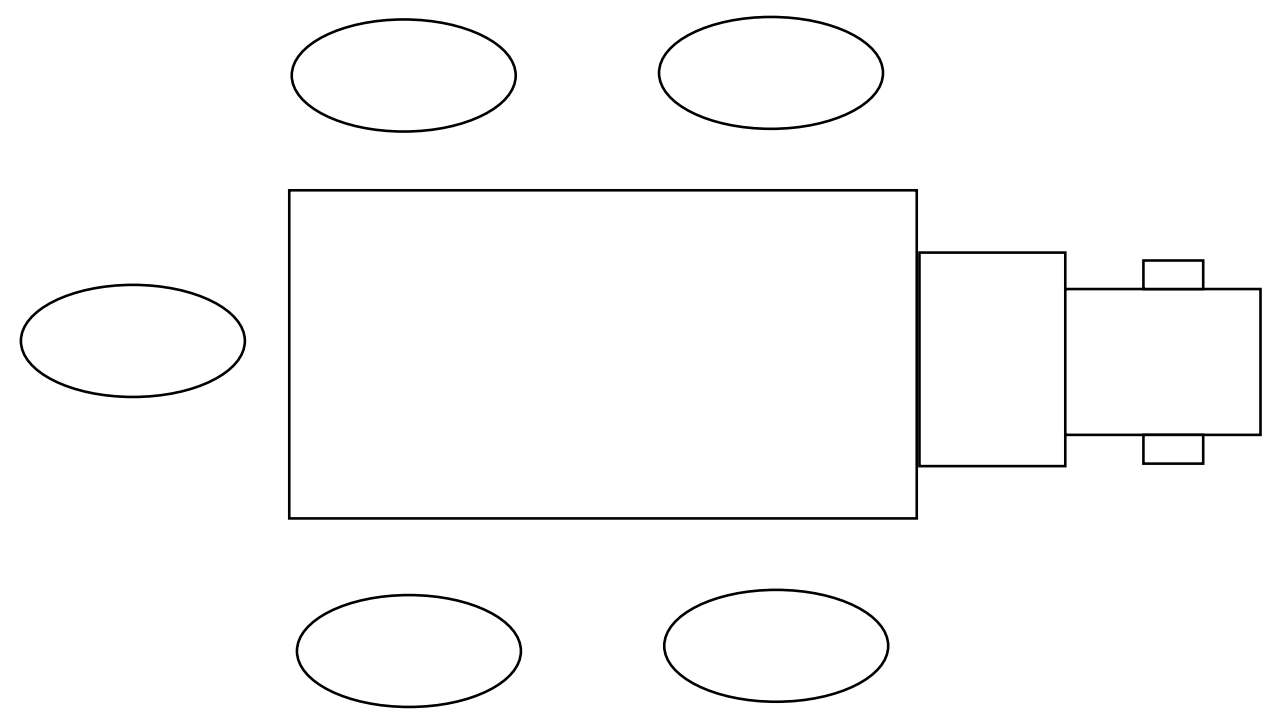

\section{Gamma and Neutron Information}

Personal radiation detector (PRD) reading of "9" observed? $\quad$ YES NO Maximum PRD reading observed:

Maximum Survey Meter (TSA 470PRM or equivalent) count reading:

Maximum RIID dose rate or count reading:

Distance (in meters) from source at RIID dose rate reading " $20 \mathrm{nSv} / \mathrm{hr}$ ":

Radioisotope Identification:

Equipment used for identification:

Manufacturer/Model:

Serial Number:

Calibration Date 


\section{Assessment and Disposition}

Has the source been identified? $\quad$ YES NO

Identification(s):

Is the source consistent with the industrial neutron sources? Yes or No

Does the source match the declaration, placarding, or shipping manifest? Yes or No

What is the discrepancy?

Was a detailed inspection required? YES NO

Final Disposition:

Industrial source configured for legitimate end use

$\square$ Industrial source configured for illicit end use

Neutron Source of Concern:

INCLUDE

PHOTO

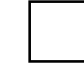

Unresolved credible radiological threat 


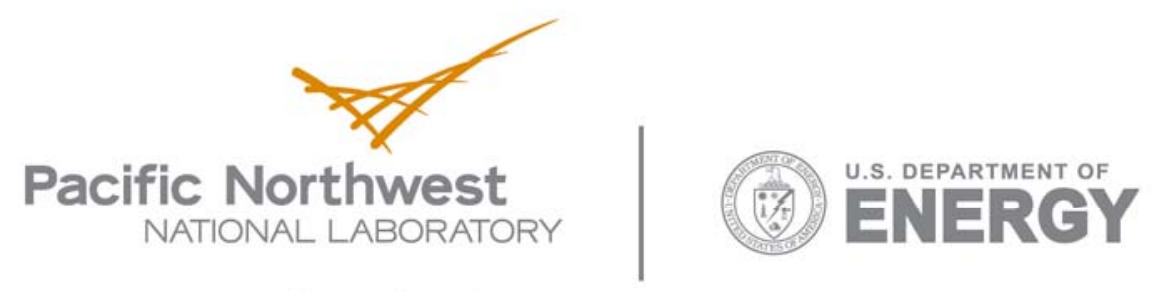

902 Battelle Boulevard

P.O. Box 999

Richland, WA 99352

1-888-375-PNNL (7665)

www.pnl.gov 